\title{
Theoretical Examination of Laser Propulsion for Aerospace Application
}

\author{
J.Sarathkumar Sebastin
}

\begin{abstract}
This paper represents the significance of laser Propulsion for Aerospace Application. Laser impetus is a type of shaft controlled drive where the vitality source is a remote laser framework and separate from the response mass. This type of drive varies from a regular concoction rocket where both vitality and response mass originate from the strong or fluid charges continued board the vehicle. The ongoing tests on laser Propulsion demonstrate that, a little quad copter has flown for 12 hours and 26 minutes charged by a $2.25 \mathrm{~kW}$ laser (controlled at not exactly $50 \%$ of its ordinary working current), utilizing 170 watt photovoltaic exhibits as the power recipient, and a laser has been shown to charge the batteries of an unmanned elevated vehicle in trip for 48 hours. For shuttle, laser electric impetus is considered as a contender to sunlight based electric or atomic electric drive for low-push impetus in space. In the present examination, correlation of execution parameters of Laser Propulsion with Solar Propulsion are assessed hypothetically.
\end{abstract}

Keywords: Beam Powered Propulsion, Solar Propulsion, laser Electric Propulsion

\section{INTRODUCTION}

Remote vitality move or remote power transmission is the transmittance of electrical vitality from a power source to an electrical burden without interconnecting wires. The most widely recognized type of remote power transmission is done utilizing direct enlistment pursued by full attractive acceptance. Different techniques under thought incorporate electromagnetic radiation as microwaves or laser bar innovation. With wired power or vitality move, we can without much of a stretch transmit vitality of extremely low to additional high worth. Be that as it may, for certain spots it will be extremely valuable if the vitality move happen without wire is required. There are various ideas utilized in the field of remote exchange innovation, these are, Transfer coupling, Resonant Induction coupling, Microwave energy transfer, Laser beam transfer, and Electrical conduction method.

In spite of the fact that there are a few techniques accessible, in commonsense cases there is no gadget for transmitting power remotely with high vitality limit. Be that as it may, at accessible in the market. The principal endeavors to transmit vitality remotely to do as such are ascribed to Nikola Tesla (1856-1943) at his lab, New York only 30 years after James Maxwell (1831-1879) had anticipated in 1873 the vehicle of vitality through vacuum by means of electromagnetic waves, approved on a fundamental level 15 years after the fact by Heinrich hertz (1857-1894). The main fruitful building way to deal with utilize microwaves for compelling vitality

Revised Manuscript Received on December 30, 2019.

* corresponding author

* J.Sarathkumar Sebastin, Asst. Professor, Department of Aeronautical Engineering, Kalasalingam academy of Research and Education, Tamilnadu, sebastinaero@gmail.com low power move there are such a large number of gadgets

transmission was finished by William dark colored in the 1960 's, by controlling among different gadgets a fastened helicopter. The bravest ideas was presumably proposed by Criswell et.al in 1990: There has as of late been a resurgence of enthusiasm for the utilization of channeled capacity to help space Exploration exercises. This paper aims on method for long distance wireless power transmission utilizing laser energy resource.

\section{LASER POWERED ENERGY TRANSMISSION}

The laser based long separation vitality transmission gear for the most part comprises of two subsystems that lead a round changing over procedure between electric vitality and light vitality. For the most part, the power - light change procedure is directed by laser asset, while the light - power transformation is led by Photovoltaic cell. (Allude Fig.1.) The powerful weight proportion of the Photovoltaic cell has dependably been yearned in the uses of flying machine and space satellite, consequently multilayer meager film photovoltaic cells are these days generally utilized in these applications. As we probably am aware, this sort of slight film photovoltaic cells has the benefits of little size, high productivity and a solid capacity of radiation obstruction, having the right to be a perfect decision for pragmatic applications.

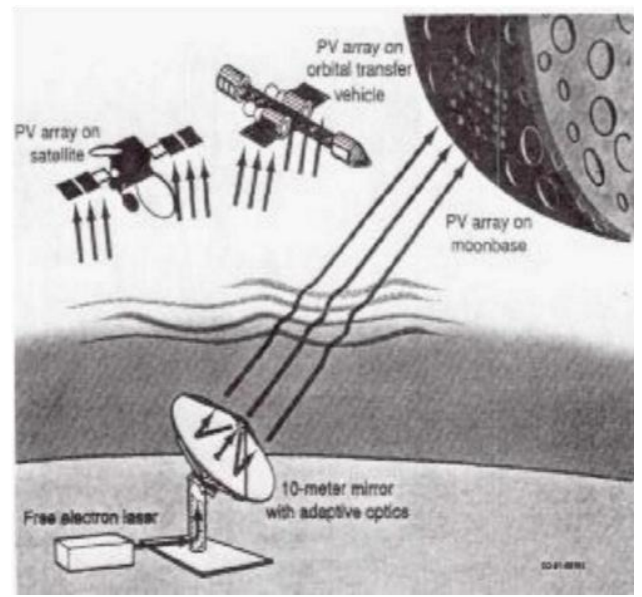

Fig.1. Application for Earth to Space Power beaming by laser

Light amplification by stimulated emission of radiation (LASER) to be viewed as must work in the wavelength range focused on the obvious range in which the air is about straightforward. Environmental retention through Ozone and Rayleigh dispersing fixed the base wavelength at around $360 \mathrm{~nm}$. 


\section{Theoretical Examination of Laser Propulsion for Aerospace Application}

The extreme wavelength is set through the reaction of the sun based cells, around 860nm for GaAs cells and around 960-1000nm for Si cells.

\section{ALTERNATIVES FOR PHOTOVOLTAIC CELLS}

Table 1 demonstrates a portion of the alternatives for photovoltaic cells which may be utilized for laser vitality transformation in different wavelength ranges. For short wavelengths, most sunlight based cells will react. Proficiency can be streamlined by utilizing a material with the most extensive conceivable band hole steady with the cutoff appeared in the above condition.

Table 1: PV Converters Cell Characteristics

\begin{tabular}{|c|l|l|l|}
\hline Sl.No. & \multicolumn{1}{|c|}{$\begin{array}{r}\text { Wave } \\
\text { length }\end{array}$} & Range & Cell Characteristics \\
\hline 1 & Visible & $0.4-$ & $\begin{array}{l}\text { Efficiency of Si or } \\
\text { GaAs cells decreases } \\
\text { linearly with k. }\end{array}$ \\
\hline 2 & $\mathrm{Si}$ & $0.8 \mu$ & $\begin{array}{l}\text { Efficiency of Si cells } \\
40 \%\end{array}$ \\
& Optimum & $1.0 \mu$ & \\
\hline
\end{tabular}

As for the photovoltaic beneficiaries, a few issues merit thought. Prediction of monochromatic performance, Operation in Pulsed mode, Temperature, Array Issues, Array Issues, Radiation Damage.

\section{CALCULATION OF LASER POWERED ENERGY CONVERSION EFFICIENCY}

The productivity of a sun based cell for monochromatic (laser) enlightenment is a lot higher than that under sun based brightening. This is principally because of two elements:

The sun creates a wide-band range, thus the majority of the sunlight based photons can't be utilized productively in a sun based cell with a solitary band hole. Photons with vitality not exactly the band hole won't be consumed, and for photons with vitality more noteworthy than the band hole, the majority of the vitality more prominent than the band hole vitality will be lost. For a monochromatic wavelength, be that as it may, the majority of the photon vitality can be helpfully ingested.

The proficiency of a sunlight based cell under monochromatic brightening at a wavelength close to the unearthly reaction pinnacle can be more than double the sun based effectiveness.

Presistance/Poutput - IR/V Consequently, for this heartbeat group the cell must be intended to limit arrangement obstruction. For instance, a high proficiency Ga As cell at 100 $\mathrm{mW} / \mathrm{cm}^{2}$

(approximately one sun) laser power would create a present thickness of $0.065 \mathrm{~A} / \mathrm{cm}^{2}$, with a working voltage close to 1 volt and arrangement obstruction of $0.05 \mathrm{Q} \_\mathrm{cm}^{2}$. At multiple times this current, $50 \%$ of the cell power will be lost by obstruction. In this way, at one sun normal force the proportion of pinnacle capacity to average power (i.e., one over the obligation cycle) can't be more than 150 preceding arrangement opposition misfortunes command the influence.

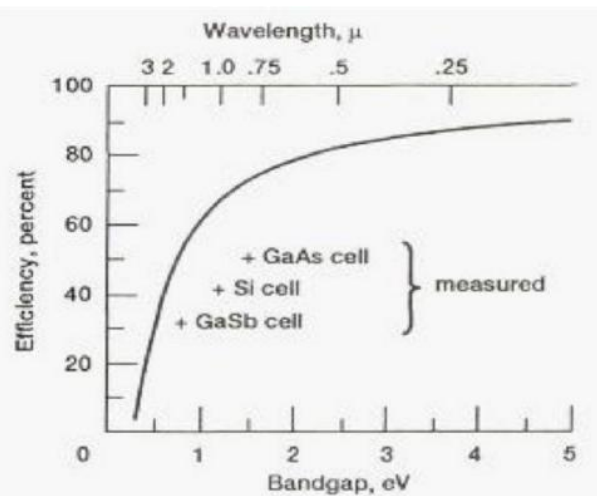

Fig.2 GaAs cell Efficiency vs band gap of the Material

The laser vitality transmission innovation is additionally connected to the little air ship for the observation of harmed territories and for the correspondence hand-off station at cataclysmic event, for example, flood, quake, fountain of liquid magma ejection, and so forth.

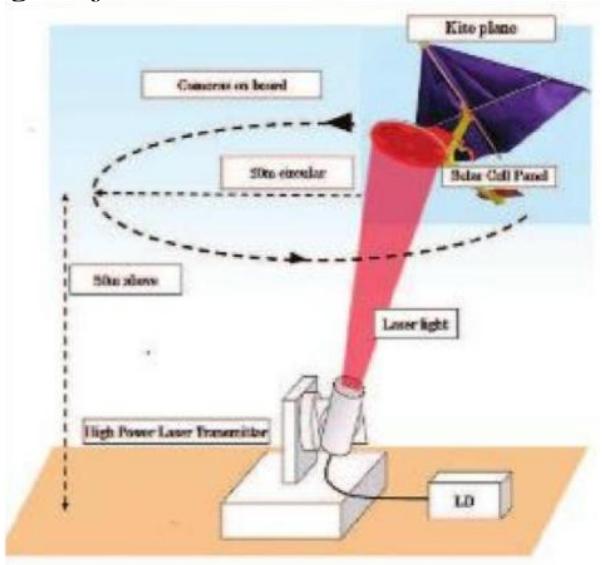

Fig.3 System configuration of a laser energy driven kite plane

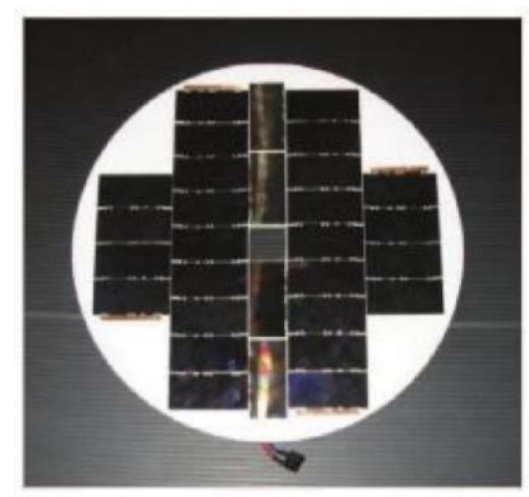

Fig.4 Solar panel for a Kite plane drive

The short circuit current density is:

$$
\begin{aligned}
& \mathrm{Jsc}(\text { laser })=\mathrm{q} \mathrm{N}(\mathrm{QE}) \\
& \mathrm{N}=\mathrm{Pin} / \mathrm{h} \gamma \mathrm{h} \gamma=\mathrm{q}(1.24 / \lambda) \\
& \text { Jsc(laser) }=\mathrm{QE} \mathrm{P}_{\text {in }}(\lambda / 1.24)
\end{aligned}
$$

$\mathrm{P}_{\text {laser }}=\mathrm{V}_{\mathrm{oc}} \mathrm{FF}$ QE Pin 0,/1.24) $\eta$ laser $=\eta \operatorname{solar} *(\operatorname{Psun} / \mathrm{Jsc}) *$ $(\mathrm{QE}) *(\lambda / 1.24)$ 


\section{RESULTS \& DISCUSSION}

Measuring PV (Ga As Cell) efficiency: Efficiency of Ga As Cell is defined as:

$\eta_{\max }=\left(\mathrm{P}_{\max }\right) \quad /$ (incident radiation flux *

Area of collector)

Assume we have a $400 \mathrm{~W}$ system with an area of $30 \mathrm{ft}^{2}$. Incident radiation flux $=1000 \mathrm{~W}$ (solar).

The maximum efficiency of Solar electric conversion is, $\eta_{\max }=14.3 \%$

$$
\underset{(38.19 \%)}{\eta_{\text {laser }}=\eta_{\text {solar }} *\left(\mathrm{P}_{\text {sun }} / \mathrm{J}_{\mathrm{sc}}\right)} *(\mathrm{QE}) *(\lambda / 1.24) \quad \eta_{\text {laser }}=0.3819
$$

Another redress to proficiency is that of working temperature. As the temperature expands, the effectiveness of transformation diminishes; this reduction is portrayed by the temperature coproficient of productivity. The temperature coeffective is included three segments; varieties in open circuit voltage, cut off, and fill factor. Expanding the temperature of the cluster results in a power transformation proficiency, which thus implies that, a greater amount of the occurrence laser power is disseminated as warmth. Consequently, this issue is exceedingly non-direct.

\section{CONCLUSION}

Laser propulsion for spacecraft using alternate PV converter cells uses the energy of laser beams. Its pronounced advantage is that it confiscates the need for the spacecraft to carry its particular source of energy and committed propulsion system. The propulsive dynamism comes instead from a fixed, high-power laser beam that is engaged onto the spacecraft by a trailing and converging system. Off-board techniques have been suggested to lift lightweight vehicles either from the ground to orbit, or on interstellar missions. These practices include laser-powered throwing to orbit and laser light sails.

\section{REFERENCES}

1. G.A. Landis, "Moon base Night Power by Laser Illumination," to be published, J. Propulsion and Power (1991)

2. G.A. Landis, "Solar Power for the Lunar Night," 9th Princeton/SSI Conf. on Space Manufacturing, Princeton, N.J. May 10-13 1989; paper published in Space Manufacturing 7, 290-296 (AIAA, 1989). Also available as NASA Technical Memorandum TM-102127 (1989).

3. G.A. Landis, "Satellite Eclipse Power by Laser Illumination," Acta Astronautica, Vol. 25 o. 4, 229-233 (1991)

4. C.A. Beiochman and S. Ridgway, "Adaptive Optics and Interferometry, Physics Today, Apr. 1991, 48-51

5. P.A. Iles, "Non-solar Photovoltaic Cells," Twenty First IEEE Photovoltaic Specialists Conf, Vol. 1, 420-425 (1990).

6. G.H. Walker et al., "Potential Converter for Laser Power Beaming Using Diode Lasers," Space Photovoltaic Research and Technology 1991, NASA CP-3121, pp. 25-1 to 25-9 (1991). [12] L. Fraas et al., Optoeleetronic Devices and Technologies, Vol. 5, No. 2, 297-310 (1990).

7. A.F. Hepp and G.A. Landis," Applications of Thin-Film PV for Space," 26th Intersociety Energy Conversion Engineering Conference, Nbl. 2, 256-261 (1991).

8. C. A. Schafer, D. Gray, Transmission media appropriate laser-microwave solar power satellite system, Acta Astronautica. 79 (2012) 140-156.

9. D. M. Flournoy, What is a solar power satellite? In: J. N. Pelton(Eds.), Solar power satellite, Springer, New York, 2012, pp. 1-8
10. Antonino Laudani, Fernando MancillaDavid, Francesco Riganti-Fulginei, Alessandro Salvini, Reduced-form of the photovoltaic five-parameter model for efficient computation of parameters, Solar Energy 97 (2013) 122-127

11. N. Amrizal, D. Chemisana, J.I. Rosell, Hybrid photovoltaic-thermal solar collectors dynamic modeling, Applied Energy 101 (2013) 797-807.

12. Erdem Cuce, Pinar Mert Cuce, Tulin Bali, An experimental analysis of illumination intensity and temperature dependency of photovoltaic cell parameters, Applied Energy

\section{AUTHORS PROFILE}

J. Sarathkumar Sebastin working as Assistant Professor in Aeronautical Engineering, Kalasalingam Academy of Research and Education. The author has published papers in the areas of Solid propellants, UAV and propulsion. 